\title{
Work Stress Symptoms and their Related Factors among Hospital Nurses
}

\author{
Li Fang ${ }^{1}$, Chin-Lin Fang ${ }^{2}$ and Shu-Hui Fang ${ }^{3}$ \\ ${ }^{1}$ Department of Nursing, Meiho University, Pingtung, Taiwan, Republic of China \\ ${ }^{2}$ Department of Rehabilitation, Division of Erlin, Changhua Christian Hospital, Changhua, Taiwan, \\ Republic of China \\ ${ }^{3}$ Department of Foreign Languages, Fooyin University, Kaohsiung, Taiwan, Republic of China
}

Correspondence should be addressed to: Shu-Hui Fang; en013@yahoo.com.tw

Received date: 28 November 2014; Accepted date: 11 March 2015; Published date: 1 July 2016

Academic Editor: Toshiyuki Yasui

Copyright (C) 2016. Li Fang, Chin-Lin Fang and Shu-Hui Fang . Distributed under Creative Commons CC-BY 4.0

\begin{abstract}
s
Most studies were limited to explore work stress symptoms of the hospital nurses due to work only, and work stress symptoms from factors related to family environments were neglected.This study was to explore the nurses' work stress symptoms and the influences of demographic characteristics, family, and nursing work environments on the degrees of the stress symptoms. 166 nurses were recruited from a regional teaching hospital. Cross-sectional and repeated measures designs were used in this study.The results were shown as follows: (1) The daily average number of symptoms among hospital nurses was 5.92 symptoms/ per person, and the top three stress symptoms of the hospital nursing staff during the 5 working days are fatigue, neck and shoulder pains and back pain. (2) The affecting factors of work stress symptoms were correlated with family-work conflicts, self-perceived stress from nursing work and working years of this job.(3) The main factors related to workstress symptoms among nurses was the working years of this job, and each extra working year will relieve 0.153 stress symptoms from each nurse.It was recommended that the managers of the hospital could set up a 24-hour nursery, to ease the conflicts between work and domestic roles among nurses. In addition, the workplace should arrange in-service educations related to positive stress coping strategies. Future studies should apply the longitudinal follow-up design, and undergo the effectiveness of the educational programs on stress adaptation strategies.
\end{abstract}

Keywords: hospital's nurses, stress symptoms, work stress.

Cite this Article as: Li Fang, Chin-Lin Fang and Shu-Hui Fang (2016), "Work Stress Symptoms and their Related Factors among Hospital Nurses", JMED Research, Vol. 2016 (2016), Article ID 746495,

DOI: $10.5171 / 2016.746495$ 


\section{Introduction}

The corporate work environment has become more stressful over time because of the merging, downsizing, and increasing competition (Salmond \&Ropis, 2005). Nurses workplace has experienced the same kind of stress. Harris (1989) indicated that compared with the general population, surgical nurses had a higher mortality rate, more anxiety, depression, and stress-related diseases. Half of workplace absenteeism and $40 \%$ of employee turnover were caused by work stress, which cost $\$ 200$ to $\$ 500$ billion annually on the treatment expenses (Salmond \&Ropis, 2005). Nursing staffs faced work stress for a long term; if work stress could not be relieved, it will lead to burnout, absenteeism or to quitting the work (Lim, Bogossian\& Ahern, 2010).

Stressful situations may lead to cognitive, emotional, and physical responses (Sheu, Lin, \& Hwang, 2002). Negative symptoms of stress include physical, psychological, and behavioral symptoms such as increased heart rates, headaches, ulcers, anxiety, anger, and substance abuses (Sheu, Lin, \& Hwang, 2002). According to Jamal and Baba's study (2000), workstress among nurses and nursing managers was significantly correlated with psychosomatic symptoms. These symptoms included headaches, upset stomachs, sleep disturbances, disturbances in bowel movement, losses of appetite, nervousness, and morning sicknesses. Yeung,Genaidy, Deddens and Sauter (2005) carried out a cross-sectional study among 97 female registered nurses. They found that over workload was associated with musculoskeletal symptoms including discomfort of the back, hands/wrists, and legs. Nadaoka, Kanda and Oiji (1997) indicated that more than $40 \%$ of nurses reported recurrent headache related to work stress. According to the study of Krantz, Berntsson, and Lundberg (2005), the most prevalent and severe symptom of stress in women was shoulder and neck pain, followed by headaches and sleep disturbance.
Krantz, Berntsson, and Lundberg (2005) underwent surveys of 1338 white-collar employees (743 women; 595 men) by mailed questionnaires. They found that the frequency and severity of stress symptoms were higher in women than in men. The women's health conditions were related to the loading of their worksand household duties. Guppy and Guttering (1991) indicated that $85 \%$ of nurses' stressors were due to heavy workload. Chen (2006) underwent a survey of 686 and 861 nurses who worked in a regional hospital and a medical hospital respectively. Chen found that nurses with heavy workload had 1.7 to 2.9 times risk of stress-related symptoms compared with those with proper workload.China, Guoa, Hung,Yang, and Shiao (2014) indicated that lack of sleep is a common problem among hospital nurses and their short sleep duration was correlated to their high work stress.

According to the study by Hou (1984), the youngest and least experienced nurses had more psychological symptoms related to stress, such as anxiety, fatigue, depression, and low self-esteem. However, the level of stress was not correlated to the nurses' educational level and their family's financial status (Hou, 1984). Moreover, there were no differences between the level of stress and the different work settings among nurses (Hou, 1984).Taylor (1995) compared the level of work stress between nurses working in emergency department and critical care units, and found that work stress was not significantly different between the two groups.

However, most studies were limited to work stress symptoms caused by work only, and the workstress symptoms from the factors related to family environments were mostly neglected. Previous studies regarding stress symptoms among nurses were cross-sectionally designed (Krantz, Berntsson, \& Lundberg, 2005; Hou, 1984; Chen , 2006). Biases existed in those types of study designs because an individual's perception of stress and the appearance 
frequency of stress symptoms might change over time. We appliedfive consecutive repeated measures for nurses' stress symptoms and obtained the average days for presence of the symptoms to avoid the bias. Therefore, the purposes of this study were to explore the nurses' stress symptoms related to their demographic characteristics, and family and nursing work environments respectively and the degrees of stress symptoms in a regional hospital in south Taiwan. In particular, the focus was on the nurses' stress symptoms due to burdens from both their nursing work and family. Hopefully, the results of this study could provide for health policy makers with a possible solution to alleviate nurses' stress and stress symptoms.

The specific aims of this study were to explore the following: (1) the nurses' stress symptoms in Taiwanese nurses working in a regional hospital ; (2) the relationships among demographic characteristics, family, nursing work environments and the number of the nurses' stress symptoms in Taiwanese nurses working in a regional hospital; and (3) the independent variables (demographic characteristics, family, and nursing work environments) which best predict the degrees of the stress symptoms in Taiwanese nurses working in a regional hospital.

\section{Methods}

Cross-sectional and repeated measures designs were used in this study. Five consecutive repeated measures for nurses' stress symptoms were collected in self-reported questionnaires at the end of each day duty for 5 days.

\section{Samples and Settings}

166 participants who worked in this regional teaching hospital were recruited. Director, supervisors, and head nurses were excluded. After obtaining IRB approval from the hospital and the signed informed consent from research participants, the questionnaires were distributed to the 166 nurses. Nurses were asked to complete a self administered questionnaire consisting of 4 parts. They included demographic characteristics, family condition, nursing work environments and stress symptoms. The data of each nurse were collected for a five consecutive days. Five consecutive repeated measures for stress symptoms were collected at the end of each day for 5 days. Two research assistants went to the nurse station in 30 minutes at the end of the duty for 15 minutes in order to remind the participants of completing the questionnaires

\section{Instruments and Validity}

A structured questionnaire was developed by the researcher.A focus group consisted of nurses in various specialities was held to improve the questionnaires content validity. The validity of the original form of the questionnaire was validated by 5 reviewers: Two experienced nurses and one new nurse working in the hospital shorter than one year, a head nurse working in the psychiatric ward, and a professor who expertized in statistics and research methodology, who was a research fellow in a health promotion agency. Five reviewers were asked to express their opinions on the questionnaires in terms of its appropriateness. Modifications and deletions of the contents were made according to the experts' opinions. The assessment was conducted by using Content Validity Index (CVI). The average CVI value was 0.92 . Cronbach's $\alpha$ for stress symptoms' was 0.88 . A 16-item questionnaire was divided into 4 parts: demographic characteristics, family, nursing workenvironments and stress symptoms.

Demographic Characteristics. The participants' ages, the importance of religion, educational backgrounds, and working years for nursing workwere included.

Family. Family environments included whether havingperson for emotional supportr not, perceived burden of the family financial status, working hours per-week on household, conflicts between household and 
workcommitments.

Nursing Work Environments. Nursing work environments included the working setting, work positions, self- perceived work stress, shift types, work hours a day, patient numbers for care, and whether alone or not on the duty shift.

Stress Symptoms. The instrument developed was based on the record of a focus group of 10 nurses in the hospital. All stress symptoms that they had ever experienced were recorded. A total of 23 stress symptoms included fatigue, shoulder pain, back pain, insomnia in last night, feeling anxiety, feeling upset stomach, agitation , lack of patience, headaches, forgetfulness, anger, dis-concentration, upset stomach, palpitation, excessive restlessness, loss of appetite, work-related errors, with dizziness, numbness on fingers or toes, diarrhea, oral ulcers, crying and herpes simplex eruptions (lips or body).

\section{Data Analysis}

Data were analyzed by using the Statistical Package for Social Science (SPSS, Inc., Chicago, IL, USA) 13.0 for Windows. Pearson correlation and one-way ANOVA were used for examining whether demographic characteristics, family environments, and nursing workenvironments were related to the level of stress symptoms. Demographic data were also examined by descriptive statistics, which included the distribution of the largest, smallest, frequency, percentage, mean, mode, and standard deviation. The mixed model was used to identify the major significant risk factor.

\section{Results}

The frequency of the 23 stress symptoms during the 5 days observation

The daily average number of symptoms among hospital nurses was 5.92 symptoms/ per person, and the top three stress symptoms of the hospital nursing staff during the 5 working days were fatigue, neck and shoulder pains and back pains(table 3). According to the univariate analysis, the affecting factors of workstress symptoms were correlated with family-work conflicts, self-perceived stress from nursing work and working years of the job. The main factors related to workstress symptoms among nurses was the working years of this job, and each additional working year will relieve 0.153 stress symptoms from nurses.

According to table 1 , the greatest frequent stress symptom was fatigue, which was shown in $38.55 \%$ nurses for5 observation days, $13.86 \%$ nurses showed fatigue for 5 observation days, and only $10.84 \%$ nurses did not have fatigue symptoms during the 5 observation days among 166 nurses. The average days for presence of the fatigue were 3.28 days among 166 nurses. The second stress symptom was shoulder pains which were present in $36.85 \%$ nurses for5 observation days. The average days for the presence of the shoulder pain were 2.88 days among 166 nurses. The third stress symptoms was back pain which was presented in $28.93 \%$ for 5 observation days among 166 nurses, and the average days for the presence of back pains were 2.15 days per nurse. The least symptoms were herpes (lips or body) which were 0.13 days pernurse during 5 observation days.

\section{Demographic Characteristics}

Table 2 shows the nurses' demographic characteristics in this study. The mean age of the 166 nurses was 31.34 years old, and the mean clinical nursing working experience was 6.62 years. In terms of education levels, 83 nurses had bachelor's degrees (50\%), followed by 74 with specialist college degrees $(44.6 \%)$, while vocational college comprised the smallest proportion, $0.6 \%$. One hundred and fifty-seven nurses (94.6\%)hada person for emotional support. Subjectively, 95 nurses $(57.2 \%)$ perceived their family financial burdens as "median," followed by "low" in 40 nurses $(24.1 \%)$ and "high" in 31 nurses (18.7\%). In terms of 
conflicts between household chores and work commitments, 79 nurses (47.6\%) reported "low" conflicts while 73 nurses (44\%) reported "high" conflicts. In terms of present service units, 52 nurses (31.3\%) were working in intensive care units, 45 nurses $(27.1 \%)$ were working in surgical wards, 37 nurses $(22.3 \%)$ were working in medical wards, 18 nurses (10.8\%) were working in operating rooms, and 14 nurses $(8.4 \%)$ were working in emergency rooms.

According to table 2, 151 (91\%) were staff nurses. One hundred nurses $(60 \%)$ perceived stress resulting from nursing work as "moderate", and only 9 nurses (5.4\%) perceived stress as "low".

Related Factors Affecting the Number of Self-perceived Work Stress Symptoms in Nurses

After statistical testing and analysis (one-way ANOVA), the univariate analysis of nominal variables affecting the number of self-perceived work stress symptoms among nurses (Table 4) showed that the number of self-perceived work stress symptoms in nurses is correlated to the degrees of conflicts between household chores and work commitments $(\mathrm{F}=4.055, \mathrm{p}<0.05)$, and the degrees of stress resulting from nursing work $(\mathrm{F}=15.104, \mathrm{p}<0.05)$. After Post-Hoc analysis, the number of stress symptoms in nurses who perceived the degree of stress resulting from nursing work as "low" was 2.422 less than those who perceived the degree of stress as "moderate" with 4.956 . Having a person for emotional support or not and perceiving high family financial burdens or not were not associated with nurses' stress symptoms. Nurses' work places, the importance of religions, education levels, workpositions, shift types, and the length of working years were also not correlated to the number of self-perceived work stress symptoms among nurses.

Pearson correlation was used to determine the association between the number of self-perceived work stress symptoms among nurses and the continuous variables (Table 5). It was found that the number of self-perceived work stress symptoms in nurses was significantly correlated with the working years of the job $(r=-0.192, p=0.013)$, which was a negative correlation. This indicated that the number of stress symptoms decreased with the increased working years of the job. The age of the nurses and the total working hours per-week on household chores were not statistically correlated with the degrees of self-perceived work stress symptoms among nurses. The major factors that correlated with the number of self-perceived work stress symptoms in nurses were identified. From Table 6, it can be seen that the major factor that correlated with the number of self-perceived work stress symptoms in nurses was the working years of the job, and each extra working year will relieve 0.153 stress symptoms from nurses.

\section{Discussion and Conclusion}

The top three stress symptoms of the hospital nursing staff during the 5 working days were fatigues, neck and shoulder pains and back pains. The results of the stress symptoms rankings were similar to the results obtained by Krantz, Berntsson and Lundberg (2005); shoulder and neck pains and headaches were among the top 3 symptoms. When the nurses felt persistent fatigue, shoulder pain and back pain symptoms, they should timely review what caused them pressure, and further sought for the resolutions. The main factor related to workstress symptoms among nurses was the length of working years. This result is consistent with the studies of Hou (1984) and Su (1993), which suggested that nurses with fewer working years were relatively inexperienced, and lacked the resources for making on-the-spot decisions. They felt that they were unable to handle their work confidently, and therefore, they had a higher stress levels. Hou (1984) indicated that the youngest and least experienced nurses had more psychological symptoms related to stress such as anxiety, fatigue, depression 
and low self-esteem. Hou (1984) indicated thatthere was no relationship among the degrees of stress, the educational levels and the financial status of the family. This was consistent with the result as shown in Table 4 on educational levels and the financial status of the family. In our study, there was no relationship between workplaces and work stress symptoms. This result was consistent with Hou (1984) and Taylor (1995). The nurses who worked in emergency room or intensive care unit may take care of more critical patients than general surgical wards and medical wards. However, the man power in the emergency room or the intensive care unit was more than the man power in the general surgical wards and medical wards. Therefore, the support system was stronger.

The number of self-perceived work stress symptoms in nurses (Table 4) showed that the number of self-perceived work stress symptoms in nurses were correlated to the degrees of conflicts between household chores and work commitments $(\mathrm{F}=4.055$, $\mathrm{p}<0.05$ ). The major sources of stress for women resulted from the conflicts at work and at home (Sauter\& Swanson, 1996; Hurrell\& Murphy, 1992). When an employee often failed to take into account family role and workduty, they will face the occupation and domestic role conflicts, and which would easily lead to stress (Martin-Fernandez, Ignacio, Cazorla, \& Martinez-Falero, 2009).According to the author's personal experience and discussions with colleagues, the author learned that early childhood care was the possible stressor for the nursing staff. Therefore, the managers of the hospital could set up a 24-hour nursery for the nurses' babies, to ease the conflicts between work and domestic roles among nurses. Li (2004) mentioned that appropriate strategies might relieve stress processes. It is recommended that the managers of the hospital could set up a 24-hour nursery, to ease the conflicts between work and domestic roles among nurses. If nurses were familiar with the strategies of relieving stress, they could adapt to the process of pressure, and avoid stress symptoms. Therefore, the nurses' managers should arrange in-service education related to positive coping strategies to cultivate the coping skills of nurses and decrease the negative outcomes of stress.

The measurements of the degrees of stress for previous studies applied recall methods to let people recall stress experiences one to 4 weeks before. It would lead to recalled bias. This current study explored the degree of stress by asking nurses the number of stress symptoms at the end of the duty to avoid recalled bias. This is a cross-sectional study which can not verify cause effect relationship. Future studies should apply longitudinal follow-up design and undergo the effectiveness of the educational programs on stress adaptation strategies.

\section{References}

1. Fairbrother, K. \& Warn, J. (2003) "Workplace Dimensions, Stress and WorkSatisfaction,"Journal of Managerial Psychology, 18(1) 8-21.

2. Chen, W. L. (2006) "Factors affecting musculoskeletal disorders among hospital nurses. "Mid-Taiwan Journal of Medicine, 11(4) 252-260.

3. Taylor, D.H. (1995)"Comparison of level \& sources of stress between critical care, emergency department and flight nurse," Air Medical Journal, 14(3)177.

4. China, W., Guo, Y.L., Hung, Y.J., Yang, C.U., \&Shiao, S.C. (2014)"Short sleep duration is dose-dependently related to workstrain and burnout in nurses: A cross sectional survey.

5. International journal of nursing studies,"http://dx.doi.org/10.1016/j.ijnurstu .2014.09.003

6. Hou, W. L . (1984) "Evidenced based research on job stress, "Management Review, 338-346. 
7. Su, H. R., Chou, S. Y., Yuan, S. C., Kuo, H. H., Yang, J. S., \&Kuo, H. W. (1993) "The study of job stressors and stress response of clinical nurses," Nursing Research, 1(1) 83-92.

8. Harris, R. B.(1989) "Reviewing nursing stress according to a proposed coping adaptation framework, " Advances in Nursing Science 11(2) 12-28.

9. Hurrell J, Murphy L.(1992)." Psychologicalworkstress in environmental and occupational Medicine," Boston: Little Brown and Company: pp 675-84.

10.Jamal, M.,\& Baba, V. V.( 2000) "Job stress and burnout among Canadian managers and nurses: an Empirical examination," Canadian Journal of Public Health, 91(16) 454-458.

11.Krantz, G, Berntsson, L., \& Lundberg, U.( 2005)"Total workload, work stress and perceived symptoms in Swedish male and female white-collar employees," European Journal of Public Health, 15(2)209-214.

12.Lee, I. (2004)" Work Stress, Coping Strategies, and Consequences among Public Health Nurses--Based on an Interactive Model," Taiwan J Public Health, 23(5)398-405.

13.Lim, J., Bogossian, F. \& Ahern, K. (2010)."Stress and coping in Australian nurses: a systematic review," International Nursing Review, 57(1)22-31.
14.Martin-Fernandez $\mathrm{S}$, Ignacio de los $\mathrm{R}$, Cazorla A, \& Martinez-Falero F (2009) "Pilot study on the influence of stress caused by the need to combine work $\backslash$ and family on occupational accidents in working women," Safety Science, 47(2), 192 - 198.

15.Nadaaka, T., Kanda, H.,\&Oiji , A. (1997) "Headache and stress in a group of nurses and government administrators in Japan," JPN-HEADACHE,37(6)386-391.

16.Salmond, S., \&Ropis, P.E. (2005)"Job stress and general well-being: A comparative study of medical-surgical and home care nurses," Medsurg Nursing, 14(5)301-309.

17.Sauter S. \& Swanson N. (1996) " Psychosocial Factors and Musculoskeletal Disorders in Office Work," New York: Taylor and Francis, pp3-21.

18.Sheu, S., Lin, H.S., \& Hwang, S.L.( 2002) "Perceived stress and physio-psycho-social status of nursing students during their initial period of clinical practice: The effect of coping behavior," International Journal of Nursing Studies, 39(2) 165-175.

19.Yeung, S.S., Genaidy, A., Deddens, J., \&Sauter, S. (2005) "The relationship between protective and risk characteristics of acting and experienced workload, and musculoskeletal disorder cases among nurses," Journal of Safety Research, 36(1) 85-95. 
Table 1: The percentage of stress symptoms for the number of days stress symptoms and the presence of certain symptoms for the number of days

\begin{tabular}{|c|c|c|c|c|c|c|c|c|c|c|}
\hline \multirow[b]{2}{*}{ Number of days } & \multirow[b]{2}{*}{$\mathrm{N}$} & \multicolumn{6}{|c|}{$\begin{array}{l}\text { the percentage of stress symptoms for the number of days } \\
\text { stress symptoms }\end{array}$} & \multicolumn{3}{|c|}{$\begin{array}{l}\text { the presence of } \\
\text { certain symptoms } \\
\text { for the number of } \\
\text { days }\end{array}$} \\
\hline & & 0 day & 1 day & 2 days & 3 days & 4 days & 5 days & mean & \pm & SD \\
\hline 1 with fatigue & 166 & $10.84 \%$ & $9.64 \%$ & $13.86 \%$ & $12.65 \%$ & $13.86 \%$ & $38.55 \%$ & 3.28 & \pm & 1.81 \\
\hline 2 with shoulder pain & 166 & $21.69 \%$ & $11.45 \%$ & $10.24 \%$ & $9.04 \%$ & $10.24 \%$ & $36.75 \%$ & 2.88 & \pm & 2.05 \\
\hline 3 with back pain & 166 & $41.57 \%$ & $7.83 \%$ & $8.43 \%$ & $7.23 \%$ & $6.02 \%$ & $28.92 \%$ & 2.15 & \pm & 2.16 \\
\hline 4 with insomnia in last night & 166 & $33.73 \%$ & $13.86 \%$ & $13.86 \%$ & $11.45 \%$ & $4.82 \%$ & $22.29 \%$ & 2.07 & \pm & 1.95 \\
\hline 5 with feeling anxiety & 166 & $39.16 \%$ & $14.46 \%$ & $11.45 \%$ & $8.43 \%$ & $7.83 \%$ & $18.67 \%$ & 1.87 & \pm & 1.95 \\
\hline 6 with feeling agitated & 166 & $40.96 \%$ & $16.27 \%$ & $15.06 \%$ & $7.23 \%$ & $5.42 \%$ & $15.06 \%$ & 1.65 & \pm & 1.83 \\
\hline 7 with lack of patience & 166 & $42.17 \%$ & $16.27 \%$ & $15.06 \%$ & $6.02 \%$ & $7.23 \%$ & $13.25 \%$ & 1.60 & \pm & 1.8 \\
\hline 8 with headaches & 166 & $44.58 \%$ & $13.86 \%$ & $15.66 \%$ & $6.63 \%$ & $6.02 \%$ & $13.25 \%$ & 1.55 & \pm & 1.8 \\
\hline 9 with forgetfulness & 166 & $43.98 \%$ & $17.47 \%$ & $10.84 \%$ & $9.64 \%$ & $7.83 \%$ & $10.24 \%$ & 1.51 & \pm & 1.74 \\
\hline 10 with anger & 166 & $50.60 \%$ & $10.24 \%$ & $18.07 \%$ & $6.63 \%$ & $5.42 \%$ & $9.04 \%$ & 1.33 & \pm & 1.67 \\
\hline 11 with disconcentration & 166 & $53.61 \%$ & $13.86 \%$ & $11.45 \%$ & $9.04 \%$ & $2.41 \%$ & $9.64 \%$ & 1.22 & \pm & 1.66 \\
\hline 12 with upset stomach & 166 & $54.82 \%$ & $17.47 \%$ & $10.24 \%$ & $5.42 \%$ & $4.82 \%$ & $7.23 \%$ & & \pm & 1.57 \\
\hline 13 with palpitation & 166 & $60.24 \%$ & $9.64 \%$ & $10.84 \%$ & $5.42 \%$ & $8.43 \%$ & $5.42 \%$ & 1.08 & \pm & 1.6 \\
\hline $\begin{array}{l}14 \text { with excessive } \\
\text { restlessness }\end{array}$ & 166 & $68.07 \%$ & $7.23 \%$ & $6.63 \%$ & $3.61 \%$ & $7.83 \%$ & $6.63 \%$ & 0.96 & \pm & 1.63 \\
\hline 15 with loss of appetite & 166 & $62.65 \%$ & $14.46 \%$ & $7.23 \%$ & $6.63 \%$ & $3.01 \%$ & $6.02 \%$ & 0.91 & \pm & 1.48 \\
\hline 16 with work-related errors & 166 & $67.47 \%$ & $12.05 \%$ & $4.82 \%$ & $4.82 \%$ & $3.61 \%$ & $7.23 \%$ & 0.87 & \pm & 1.55 \\
\hline 17 with increased appetite & 166 & $65.66 \%$ & $12.05 \%$ & $8.43 \%$ & $6.02 \%$ & $2.41 \%$ & $5.42 \%$ & 0.84 & \pm & 1.43 \\
\hline 18 with dizziness & 166 & $71.08 \%$ & $9.04 \%$ & $4.82 \%$ & $5.42 \%$ & $2.41 \%$ & $7.23 \%$ & 0.81 & \pm & 1.53 \\
\hline $\begin{array}{l}19 \text { with numbness on fingers } \\
\text { or toes }\end{array}$ & 166 & $77.11 \%$ & $4.82 \%$ & $5.42 \%$ & $4.22 \%$ & $3.61 \%$ & $4.82 \%$ & 0.67 & \pm & 1.41 \\
\hline 20 with diarrhea & 166 & $72.89 \%$ & $14.46 \%$ & $3.61 \%$ & $3.61 \%$ & $1.81 \%$ & $3.61 \%$ & 0.58 & \pm & 1.22 \\
\hline 21 with oral ulcers & 166 & $82.53 \%$ & $4.82 \%$ & $3.61 \%$ & $3.61 \%$ & $1.81 \%$ & $3.61 \%$ & 0.48 & \pm & 1.22 \\
\hline 22 Crying & 166 & $91.57 \%$ & $4.22 \%$ & $2.41 \%$ & $0.60 \%$ & $1.20 \%$ & $0.00 \%$ & 0.16 & \pm & 0.6 \\
\hline $\begin{array}{l}23 \text { Herpes simplex eruptions } \\
\text { (lips or body) }\end{array}$ & 166 & $93.98 \%$ & $3.61 \%$ & $0.60 \%$ & $0.00 \%$ & $0.60 \%$ & $1.20 \%$ & 0.13 & \pm & 0.67 \\
\hline
\end{tabular}


Table 2:Demographic characteristics and distribution of the variables

\begin{tabular}{|c|c|c|c|c|c|c|c|c|}
\hline Variables & $\mathbf{n}$ & $\%$ & Mean & SD & Smallest & 25Percentile & Median & 75 Percentile \\
\hline Working years of the job & 166 & & 6.622 & 5.766 & 0.5 & 2.25 & 5.2 & 8.9 \\
\hline $\begin{array}{l}\text { Working hours per-week on household } \\
\text { chores }\end{array}$ & 166 & & 22.193 & 25.560 & 0 & 2.5 & 14.5 & 28 \\
\hline \multicolumn{9}{|l|}{ The importance of religion } \\
\hline not important & & 54.819 & & & & & & \\
\hline \multicolumn{9}{|l|}{ Educational levels } \\
\hline High school & 1 & 0.602 & & & & & & \\
\hline Junior college & 74 & 44.578 & & & & & & \\
\hline University & 83 & 50 & & & & & & \\
\hline Graduate school & 8 & 4.820 & & & & & & \\
\hline \multicolumn{9}{|l|}{ With a person for emotional support } \\
\hline With & 157 & 94.578 & & & & & & \\
\hline \multicolumn{9}{|l|}{$\begin{array}{l}\text { The degrees of self-perceived burden } \\
\text { on family financial status }\end{array}$} \\
\hline Low & 40 & 24.096 & & & & & & \\
\hline Median & 95 & 57.229 & & & & & & \\
\hline High & 31 & 18.675 & & & & & & \\
\hline \multicolumn{9}{|l|}{$\begin{array}{l}\text { Conflicts between household and work } \\
\text { commitments }\end{array}$} \\
\hline Low & 79 & 47.59 & & & & & & \\
\hline Median & 73 & 43.976 & & & & & & \\
\hline High & 14 & 8.434 & & & & & & \\
\hline \multicolumn{9}{|l|}{\begin{tabular}{|l|} 
Workplaces \\
\end{tabular}} \\
\hline Operation room & 18 & 10.843 & & & & & & \\
\hline Surgical ward & 45 & 27.108 & & & & & & \\
\hline Medical ward & 37 & 22.289 & & & & & & \\
\hline Emergency room & 14 & 8.434 & & & & & & \\
\hline Intensive care unit & 52 & 31.325 & & & & & & \\
\hline \multicolumn{9}{|l|}{ Work positions } \\
\hline Associated head nurse & 6 & 3.615 & & & & & & \\
\hline Head nurse & 9 & 5.422 & & & & & & \\
\hline Nurse staff & 151 & 90.964 & & & & & & \\
\hline \multicolumn{9}{|l|}{$\begin{array}{l}\text { The degrees of perceived stresses from } \\
\text { nursing jobs }\end{array}$} \\
\hline Low & 9 & 5.422 & & & & & & \\
\hline Median & 100 & 60.241 & & & & & & \\
\hline High & 57 & 34.337 & & & & & & \\
\hline
\end{tabular}


Table 3 :The distributions of variables

\begin{tabular}{|l|l|l|c|l|c|c|c|c|c|}
\hline Variables & $\mathbf{n}$ & $\mathbf{0}$ & Mean & SD & Smallest & 25Percentile & Median & 75Percentie & Largest \\
\hline $\begin{array}{l}\text { Total working hours } \\
\text { today }\end{array}$ & 830 & & 8.93 & 1.55 & 2 & 8 & 9 & 9.5 & 18 \\
\hline $\begin{array}{l}\text { Average symptoms } \\
\text { /per-person/per-day }\end{array}$ & 830 & & 5.92 & 4.87 & 0 & 2 & 5 & 9 & 21 \\
\hline Shifts & & & & & & & & & \\
\hline Day shift & 427 & 51.4 & & & & & & & \\
\hline Evening shift & 222 & 26.7 & & & & & & & \\
\hline Night shift & 169 & 20.4 & & & & & & & \\
\hline Duty shift & 12 & 1.4 & & & & & & & \\
\hline
\end{tabular}


Table 4 :Univariate analysis of factors affecting the number of symptoms related to work stress, ordered by categorized variables

\begin{tabular}{|c|c|c|c|c|c|c|}
\hline Variable & No. & Mean & SD & F value & P value & Post Hoc test \\
\hline Is religion important to you? & & & & 0.586 & 0.445 & \\
\hline No & 91 & 6.176 & 4.381 & & & \\
\hline Yes & 75 & 5.648 & 4.468 & & & \\
\hline Educational levels & & & & 0.230 & 0.825 & \\
\hline Vocational college & 74 & 5.927 & 4.248 & & & \\
\hline Specialist college & 83 & 5.925 & 4.651 & & & \\
\hline Bachelor's degree & 8 & 6.625 & 3.918 & & & \\
\hline Master's degree & 1 & 2.2 & . & & & \\
\hline $\begin{array}{l}\text { With a person for emotional } \\
\text { support }\end{array}$ & & & & 1.143 & 0.287 & \\
\hline without & 9 & 7.467 & 3.077 & & & \\
\hline with & 157 & 5.85 & 4.471 & & & \\
\hline $\begin{array}{l}\text { The degree of self-perceived } \\
\text { burden on family financial status }\end{array}$ & & & & 1.545 & 0.216 & \\
\hline Low & 40 & 5.105 & 3.744 & & & \\
\hline Median & 95 & 5.956 & 4.528 & & & \\
\hline High & 31 & 6.955 & 4.77 & & & \\
\hline $\begin{array}{l}\text { Conflicts between household } \\
\text { chores and work commitments }\end{array}$ & & & & 4.05522 & 0.019 & \\
\hline Low & 79 & 4.932 & 4.099 & & & Low $<$ Moderate \\
\hline Moderate & 14 & 6.829 & 4.63 & & & \\
\hline High & 73 & 6.855 & 4.526 & & & \\
\hline Workplace & & & & 1.00254 & 0.408 & \\
\hline Operation room & 18 & 6.633 & 4.756 & & & \\
\hline Surgical ward & 45 & 5.316 & 4.167 & & & \\
\hline Medical ward & 37 & 7 & 5.178 & & & \\
\hline Emergency room & 14 & 5.271 & 5.434 & & & \\
\hline Intensive care unit & 52 & 5.658 & 3.546 & & & \\
\hline Work positions & & & & 0.28148 & 0.755 & \\
\hline Nurse staff & 6 & 6.9 & 5.193 & & & \\
\hline Associated head nurse & 9 & 5.156 & 3.392 & & & \\
\hline Head nurse & 151 & 5.946 & 4.456 & & & \\
\hline $\begin{array}{l}\text { Self-perceived stress resulting } \\
\text { from nursing work }\end{array}$ & & & & 15.10494 & $<0.001^{* * *}$ & \\
\hline Low & 9 & 2.422 & 2.286 & & & Low $<$ high \\
\hline Moderate & 100 & 4.956 & 3.715 & & & Moderate $<$ high \\
\hline High & 57 & 8.214 & 4.828 & & & \\
\hline Shift type & & & & 1.16506 & 0.32207 & \\
\hline Day & 427 & 6.002 & 4.93 & & & \\
\hline Evening & 222 & 5.599 & 4.775 & & & \\
\hline Night & 169 & 6 & 4.798 & & & \\
\hline On-call & 12 & 8.083 & 5.632 & & & \\
\hline
\end{tabular}


Table 5: Univariate analysis of factors affecting the number of stress symptoms, ordered by continuous variables

\begin{tabular}{|l|c|c|c|}
\hline Variable & No. & Correlation coefficient & P value \\
\hline Age & 166 & 0.077 & 0.324 \\
\hline Working years of this work & 166 & -0.192 & $0.013^{*}$ \\
\hline $\begin{array}{l}\text { Working hours per-week on } \\
\text { household chores }\end{array}$ & 166 & -0.069 & 0.376 \\
\hline
\end{tabular}
${ }^{*} \mathrm{p}<0.05$

Table 6: Multivariate linear regression of factors affecting the number of stress symptoms

\begin{tabular}{|c|c|c|c|c|c|}
\hline Variable & $\begin{array}{c}\text { Correlation } \\
\text { coefficient }\end{array}$ & $\begin{array}{l}\text { Standard } \\
\text { error }\end{array}$ & \multicolumn{2}{|c|}{$95 \%$ CI } & P value \\
\hline Working years of this job & -0.153 & 0.059 & -0.27 & , $\quad-0.036$ & $0.011^{*}$ \\
\hline $\begin{array}{l}\text { Conflicts between household and } \\
\text { work commitments } \\
\text { (moderate/low) }\end{array}$ & -0.681 & 0.709 & -2.08 & , $\quad 0.721$ & 0.339 \\
\hline $\begin{array}{l}\text { Conflicts between household and } \\
\text { work commitments (high/low) }\end{array}$ & -1.724 & 1.278 & -4.25 &,$\quad 0.8$ & ) 0.179 \\
\hline $\begin{array}{l}\text { Stress resulting from nursing work } \\
\text { (moderate/low) }\end{array}$ & 0.373 & 1.519 & -2.63 & , 3.373 & ) 0.806 \\
\hline $\begin{array}{l}\text { Stress resulting from nursing work } \\
\text { (high/low) }\end{array}$ & 1.864 & 1.577 & -1.25 & , 4.978 & ) 0.239 \\
\hline
\end{tabular}

$$
{ }^{*} \mathrm{p}<0.05
$$

